\title{
Being human is a gut feeling
}

\author{
Thiago Hutter ${ }^{1}$, Carine Gimbert ${ }^{2,3}$, Frédéric Bouchard ${ }^{1}$ and François-Joseph Lapointe $2^{2^{*}}$
}

\begin{abstract}
Some metagenomic studies have suggested that less than $10 \%$ of the cells that comprise our bodies are Homo sapiens cells. The remaining $90 \%$ are bacterial cells. The description of this so-called human microbiome is of great interest and importance for several reasons. For one, it helps us redefine what a biological individual is. We suggest that a human individual is now best described as a super-individual in which a large number of different species (including Homo sapiens) coexist. New concepts of biological individuality must extend beyond the traditional limitations of our own skin to include our resident microbes. Besides its important contributions to science, microbiome research raises philosophical questions that strike close to home. What is left of Homo sapiens? If most of our cells are not Homo sapiens cells, what does it mean to be an individual human being? In this paper, we argue that the biological individual is determined by the amount of functional integration among its constitutive parts, a definition that applies perfectly to Homo sapiens and its microbiome.
\end{abstract}

Keywords: Homo sapiens, Functional integration, Biological individuality, Super-individual

\section{Background}

In the Origin of Species, Darwin posits that the process of natural selection directly acts on species by affecting the reproductive success and survival of the individuals constituting them. But what exactly are these individuals? Intuitively, we tend to think that the entities upon which selection acts are what common sense would describe as an organism, for example, a dog, a cow, and a human being. However, recent findings in various domains of biology such as physiology [1-3], sociobiology [4], microbiology [5], metagenomics [6], immunology [7], as well evolutionary transitions [8] have brought into question our intuitions concerning the correspondence between our notions of individual and organism by showing the tensions that arise between these two concepts. Such concerns have been in the heart of heated disputes in philosophy of biology [9-13], but they have not yet fully penetrated the scientific community.

By emphasizing the relation that humans have with their microbiomes, we aim to question the definition of human individuality in biological research by showing that the entity that we traditionally conceive as the organism called 'human being' is not the individual we intuitively

\footnotetext{
* Correspondence: francois-joseph.lapointe@umontreal.ca

${ }^{2}$ Département de sciences biologiques, Université de Montréal, P. O. Box

6128, Station Centre-ville, Montréal, QC H3C 3J7, Canada

Full list of author information is available at the end of the article
}

think it is. There are many ways to approach the concept of biological individuality. Here, we will focus on one particular approach in order to raise the question of individuality in humans. By focusing on the biological aspect of individuality and its relation to fitness, we distance ourselves from philosophical questions concerning selfhood and personal identity [14]. Our claim is that, with respect to most biological research projects, human beings are so well integrated with their microbiomes that the individuality of human beings is better conceived as a symbiotic entity. Insofar as biological research is concerned, to be human is to be multispecies.

\section{Main text}

Most notions of individuality in biological research have directly or indirectly called upon evolutionary considerations, but why is that? Our understanding of individuality (be it an individual chair or an individual giraffe) has historically been linked to the question of organization: an individual has often been conceived as an organized whole, distinguishing it from a mere collection of disjointed parts. For artifacts such as individual chairs, the origin of organization was easier to establish given the clear human intentionality found in the design of the artifact (that is, a chair is a functional whole that has a specific purpose because we designed and built them to have that integrated function); for biological individuals 
however, the question was much more complicated. Before Darwin, intelligent design arguments (such as the ones found in Paley) explaining the organization found in biological individuals via divine creation were the norm. Since Darwin, the origin of organization of biological individuals is to be explained thanks to designer-free adaptive processes. Individuals were functional wholes whose partsintegration was the result of evolution by natural selection.

One of the advantages of focusing on evolutionary considerations is that it also allows to account for collectives of individual organisms acting as emergent super-individuals, such as bee colonies being recognized as what is often referred to as 'super-organisms.' As suggested by E. O. Wilson [15], the question of individuality emerging from functional integration can be read in the following way: when the behaviors of members of a society - or a group - become so well organized, coordinated, and integrated that the degree of functional organization approaches - or rivals that of the integration between the parts of an individual organism, is it still truly a group of singular beings? In fact, when such a group of entities acquires such a high degree of organization, it may become fitness-bearing in the right way and thus be defined and recognized as a proper unit of selection above and beyond the individual organisms forming the group [16]. If biological individuality is to be conceived as being an evolutionary individual, the unit of selection debate will intersect with our understanding of individuality when the unit of selection achieves higher fitness thanks to higher functional integration. Here, we side with the position asserting that the functions accomplished by integrated entities are the result of collaboration between diverse entities [17]. This collaboration is sometimes between members of a same species (for example, bees) or, more controversially, between members of different species. If individuality is about organization, and if that organization in the case of biological individuals emanates from evolution by natural selection, one needs a revised account of fitness to account for the emergence of multispecies individuals.

One of the problems of accounting for the functional integration of distinct individual organisms into an emergent super-individual is that it is not obvious how to aggregate the evolutionary success (or adaptedness) of individuals with autonomous evolutionary histories. One cannot readily compare or add up the reproductive success (fitness in the traditional sense) of organism $X$ from species A to that of organism Y from species B. Interspecific fitness comparisons are usually frowned upon for that reason. Figuring out how to identify the degree of fitness alignment between organisms of different species requires the identification of a common evolutionary currency that is distinct from reproductive success. Alternative measures of fitness such as energy control [18] or differential persistence [19-21] have been suggested to allow for interspecies fitness comparisons and for fitness attributions to multispecies community level individuals. We favor the latter to account for multispecies assemblages such as the individuals that emerge from symbiotic interactions, because persistence is a necessary aspect of functional integration, whereas such integration could be achieved without fluctuations of energy control. Furthermore, the concept of persistence can also account for individuals emerging from multiple species interacting via abiotic parts of the environment [22]. In this respect, our account of biological individuality differs from others proposed in biology $[23,24]$. However, fully explaining this theory and its implications lies beyond the scope of this paper.

\section{Discussion}

How do these issues illuminate our understanding of our own biological individuality? It is common knowledge that bacterial presence is ubiquitous in every single surface of the environment exterior to any single organism and inside of it. Human beings are in constant interaction with the bacterial world, whether at the interface of their epidermis or through their digestive tract. If individuality is simply characterized by the amount of integration, the interaction between humans and microbes allows us to raise one important question: is the organism currently recognized as a human being the real individual? Indeed, the different sites of the human body are inhabited by millions of bacterial cells - the so-called human microbiome - interacting with each other as well as with human cells $[25,26]$. Such bacterial communities differ in diversity and proportion according to specific body habitats [27], which in turn ensures that each localized microbiome accomplishes different functions that affect a person's health and well-being. Namely, the gut microbiome, constituted mostly by Bacteroidetes and Firmicutes, is involved in the fermentation that enables bacteria to live in an anaerobic environment [28]. This process is used to produce short-chain fatty acid through the conversion of sugars, which are used by human cells as a source of energy. Metabolic activities of the gut microbiome also increase the amount of indispensable amino acids (that is, lysine) and contribute to the degradation of xenobiotics such as benzoate, a common food supplement involved in the biosynthesis of B9 and B12 vitamins [29]. Therefore, the bacterial communities inhabiting the human gut are an essential component of human digestion [30], and the corresponding intestinal microbiome is as important as a functional heart or kidney for survival [23]. In many respects, our microbiome-based digestion is more essential to the survival of an individual than the maintenance of other organs. In this light, being a human biological individual is to be a community of Homo sapiens and microbial symbionts whose degree of functional 
integration (and degree of individuality) is a function of the potential of that community to persist and evolve as a whole.

Because all living organisms (human beings included) rely so heavily on their microbiome to perform some of the metabolic functions that keep them alive, we claim that this symbiotic association is bound by a common evolutionary fate. The idea of common fate utilized in some accounts of biological individuality reflects the notion that the functional whole that we define as the organism and its microbiome can stand or fall as a whole when undergoing a selective pressure $[16,22]$. One notable example of such an evolutionary process is illustrated by the detrimental effects of Clostridium difficile on the functionality of the gut microbiome [31] and survival in humans [32]. At a higher level, one can also pinpoint the effect of the microbiome on reproductive success (and fitness) among closely related species and the role that gut bacteria play in speciation [33,34]. That is that, it is the sum of an organism's genome and microbiome - the hologenome - and the processes they make possible that are linked by a common evolutionary fate (extinction, speciation) and selected together as a whole $[35,36]$.

\section{Conclusions}

If individuality is a matter of being functionally integrated to the extent that the causality between the interacting parts may persist or cease when one of these parts is faced with an evolutionary pressure, we ought to consider, for biological research purposes, that the single Homo sapiens is not in fact the real biological individual. While a simpler mono-species view of individuality may be sufficient for most of our everyday social interactions, the real biological individual is a super-individual defined as the sum of the organism + its microbiome; it is this integrated symbiotic association that is able to persist and survive. As the poet Walt Whitman aptly pointed out in Song of Myself, 'I am large, I contain multitudes.'

\section{Competing interests}

The authors declare that they have no competing interests.

\section{Authors' contributions}

$\mathrm{TH}$ and CG drafted the original version of the manuscript. FB and FJL helped to revise the manuscript and edited the final version. All authors read and approved the final manuscript.

\section{Authors' information}

TH has completed a master's thesis in philosophy at Université de Montréal. CG has completed a master's thesis at the Institut national des sciences appliquées de Lyon. FB is a professor of philosophy at Université de Montréal. FJL is a professor of biological sciences at Université de Montréal.

\section{Acknowledgements}

The authors would like to thank Marianne Cloutier, Anne-Marie Gagné-Julien, Catherine Girard, Honoré Gbetoh, Alexandre Klein, Noémi Lamarre, Pier-Yves Larouche-Maltais, Maxime Leclerc, Virgine Lemieux-Labonté, Ines Levade, Sofia Rousseau-Mermans, Jesse Shapiro, and the two anonymous reviewers for their comments. Funding for this work was provided by the Social
Sciences and Humanities Research Council of Canada, and by the Natural Sciences and Engineering Research Council of Canada.

\section{Author details}

${ }^{1}$ Département de philosophie, Université de Montréal, P. O. Box 6128, Station Centre-ville, Montréal, QC H3C 3J7, Canada. Département de sciences biologiques, Université de Montréal, P. O. Box 6128, Station Centre-ville, Montréal, QC H3C 3J7, Canada. Institut national des sciences appliquées de Lyon, 20 Avenue Albert Einstein, 69621 Villeurbanne CEDEX, France.

Received: 21 November 2014 Accepted: 24 February 2015

Published online: 13 March 2015

\section{References}

1. Turner JS. The extended organism: the physiology of animal-built structures. Cambridge: Harvard University Press; 2000.

2. Turner JS. Extended phenotypes and extended organisms. Biol Philos. 2004;19:327-52.

3. Turner JS. Superorganisms and superindividuality. In: Bouchard F, Huneman P editors. From groups to individuals: evolution and emerging individuality. Cambridge: MIT Press; 2013. p. 219-41.

4. Hölldobler B, Wilson EO. The superorganism: the beauty, elegance, and strangeness of insect societies. New York: WW Norton; 2009.

5. O'Malley MA, Dupré J. Size doesn't matter: towards a more inclusive philosophy of biology. Biol Philos. 2007;22:155-91.

6. O'Malley MA, Dupré J. Towards a philosophy of microbiology. Stud Hist Philos Biol Biomed Sci. 2007;38:775-9.

7. Pradeu T. The limits of the self: immunology and biological identity. Oxford: Oxford University Press; 2012.

8. Smith JM, Szathmary E. The major transitions in evolution. Oxford: Oxford University Press; 1997.

9. Wilson RA. Genes and the agents of life: the individual in the fragile sciences biology. Cambridge: Cambridge University Press; 2005.

10. Wilson J. Biological individuality: the identity and persistence of living entities. Cambridge: Cambridge University Press; 2007.

11. Clarke E. The problem of biological individuality. Biol Theory. 2010;5:312-25.

12. Bouchard F, Huneman P. From groups to individuals: evolution and emerging individuality. Cambridge: MIT Press; 2013.

13. Godfrey-Smith P. Darwinian populations and natural selection. New York: Oxford University Press; 2009

14. Gligorov N, Azzouni J, Lackey DP, Zweig A. Personal identity: our microbes, ourselves. In: Rhodes R, Gligorov N, Schwab AP, editors. The human microbiome: ethical, legal, and social concerns. New York: Oxford University Press; 2013. p. 55-70.

15. Wilson EO. The insect societies. Cambridge: Harvard University Press; 1971.

16. Wilson DS, Sober E. Reviving the superorganism. J Theor Biol. 1989;136:337-56.

17. Dupré J, O'Malley MA. Varieties of living things: life at the intersection of lineage and metabolism. Philos Theor Biol. 2009;1:1-25.

18. Van Valen LM. Three paradigms of evolution. Evol Theor. 1989;9:1-17.

19. Thoday JM. Components of fitness. Sym Soc Exp Biol. 1953;7:96-113.

20. Bouchard F. Causal processes, fitness, and the differential persistence of lineages. Philos Sci. 2008;75:560-70.

21. Bouchard F. Darwinism without populations: a more inclusive understanding of the "Survival of the Fittest". Stud Hist Philos Biol Biomed Sci. 2011;42:106-14.

22. Bouchard F. What is a symbiotic superindividual and how do you measure its fitness? In: Bouchard F, Huneman P, editors. From groups to individuals: evolution and emerging individuality. Cambridge: MIT Press; 2013. p. 243-63.

23. Zilber-Rosenberg I, Rosenberg E. Role of microorganisms in the evolution of animals and plants: the hologenome theory of evolution. FEMS Microbiol Rev. 2008:32:723-35.

24. Godfrey-Smith P. Darwinian individuals. In: Bouchard F, Huneman P, editors. From groups to individuals: evolution and emerging individuality. Cambridge: MIT Press; 2013. p. 17-36.

25. Human Microbiome Project Consortium. Structure, function and diversity of the healthy human microbiome. Nature. 2012;486:207-14.

26. Human Microbiome Project Consortium. A framework for human microbiome research. Nature. 2012;486:215-21.

27. Zhou Y, Mihindukulasuriya KA, Gao H, La Rosa PS, Wylie KM, Martin JC, et al. Exploration of bacterial community classes in major human habitats. Genome Biol. 2014;15:R66. 
28. Tremaroli V, Bäckhed F. Functional interactions between the gut microbiota and host metabolism. Nature. 2012;489:242-9.

29. Qin J, Li R, Raes J, Arumugam M, Burgdorf KS, Manichanh C, et al. A human gut microbial gene catalogue established by metagenomic sequencing. Nature. 2010;464:59-65.

30. Rosenberg E, Zilber-Rosenberg I. Symbiosis and development: the hologenome concept. Birth Defects Res C Embryo Today. 2011;93:56-66.

31. Schubert AM, Rogers MA, Ring C, Mogle J, Petrosino JP, Young VB, et al. Microbiome data distinguish patients with Clostridium difficile infection and non-C. difficile-associated diarrhea from healthy controls. MBio. 2014:5:e01021-14.

32. Mitchell BG, Gardner A. Mortality and Clostridium difficile infection: a review. Antimicrob Resist Infect Control. 2012;1:20

33. Brucker RM, Bordenstein SR. Speciation by symbiosis. Trends Ecol Evol. 2012;27:443-51.

34. Brucker RM, Bordenstein SR. The hologenomic basis of speciation: gut bacteria cause hybrid lethality in the genus Nasonia. Science. 2013:341:667-9.

35. Rosenberg E, Zilber-Rosenberg I. The hologenome concept. In: Rosenberg E, Gophna U, editors. Beneficial microorganisms in multicellular life forms. Berlin: Springer; 2011. p. 323-40.

36. Rosenberg E, Zilber-Rosenberg I. The evolution of holobionts. In: Rosenberg E, Zilber-Rosenberg I, editors. The hologenome concept: human, animal and plant microbiota. New York: Springer; 2013. p. 109-28.

\section{Submit your next manuscript to BioMed Central and take full advantage of:}

- Convenient online submission

- Thorough peer review

- No space constraints or color figure charges

- Immediate publication on acceptance

- Inclusion in PubMed, CAS, Scopus and Google Scholar

- Research which is freely available for redistribution 